\title{
Evaluating Henry's law constant of N-Nitrosodimethylamine (NDMA)
}

\author{
Shinsuke Haruta, Wentao Jiao, Weiping Chen, Andrew C. Chang \\ and Jay Gan
}

\begin{abstract}
$\mathrm{N}$-Nitrosodimethylamine (NDMA), a potential carcinogen, may contaminate the groundwater when the reclaimed wastewater is used for irrigation and groundwater recharge. Henry's law constant is a critical parameter to assess the fate and transport of reclaimed wastewater-borne NDMA in the soil profile. We conducted a laboratory experiment in which the change of NDMA concentration in water exposed to the atmosphere was measured with respect to time and, based on the data, obtained the dimensionless Henry's law constant $\left(K_{\mathrm{H}}{ }^{\prime}\right)$ of NDMA, at $1.0 \times 10^{-4}$. The $K_{\mathrm{H}}{ }^{\prime}$ suggests that NDMA has a relatively high potential to volatilize in the field where NDMA-containing wastewater is used for irrigation and the volatilization loss may be a significant pathway of NDMA transport. The experiment was based on the two boundary-layer approach of mass transfer at the atmosphere-water interface. It is an expedient method to delineate $K_{\mathrm{H}}{ }^{\prime}$ for volatile or semi-volatile compounds present in water at low concentrations.

Key words | boundary-layer model, mass transfer, volatilization, water reuse

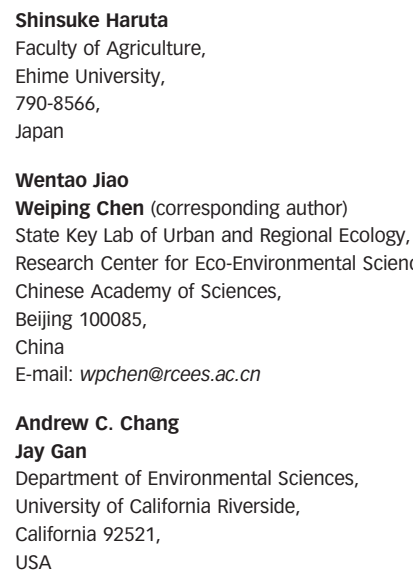

\section{INTRODUCTION}

$N$-Nitrosodimethylamine (NDMA) is a member of the carcinogen family, the $N$-nitrosamines, and is a disinfection byproduct of great concerns (Mitch \& Sedlak 2002a, b). The treated wastewater usually contains relatively high concentrations of NDMA. For instances, the mean concentration of NDMA in the chlorinated effluents of a publicly owned treatment work in California was approximately 1,000 ng/L (Gan et al. 2006) and, in a separate case, Pehlivanoglu \& Sedlak (2004) found $500 \mathrm{ng} / \mathrm{L}$ of NDMA in the reclaimed water delivered for landscape irrigation. The reported NDMA concentrations in the water are considerably higher than the $10 \mathrm{ng} / \mathrm{L}$ notification level and higher than the $300 \mathrm{ng} / \mathrm{L}$ response level set by the California Department of Health Services (CDHS 2006).

The leaching risks of NDMA with reclaimed wastewater irrigation are of concern due to its water solubility and low soil adsorption capacity (Gunnison et al. 2000; Yang et al. 2005). Gan et al. (2006) found that the soils of established turfgrass were not effective at retaining NDMA applied through the reclaimed wastewater irrigation. Haruta et al. (2008) assessed the leaching risk of NDMA in soil receiving reclaimed wastewater based on the model simulation results from HYDRUS. The results showed that while the risk of NDMA to reach the ground water was slim under the customary conditions for landscape irrigation, the risk could be significantly increased under extreme conditions. The NDMA leaching risks are highly dependent on the biodegradation and volatilization processes. Oliver (I979), Arienzo et al. (2006) and Gan et al. (2006) demonstrated that volatilization was likely a major pathway for NDMA disappearance in unsaturated soil.

Henry's law constant $\left(K_{\mathrm{H}}\right)$ is a distribution coefficient representing the equilibrium of a volatile or semi-volatile substance between the atmospheric and aqueous phases. It is an important physicochemical parameter that governs the volatilization process. A high $K_{\mathrm{H}}$ suggests that volatilization may be a significant transport process for a chemical contaminant in unsaturated soil (Jury et al. 1984).

There is not sufficient data on the $K_{\mathrm{H}}$ of NDMA. Mirvish et al. (I976) estimated that dimensionless Henry's law constant $\left(K_{\mathrm{H}^{\prime}}{ }^{\prime}\right)$ of NDMA was $1.1 \times 10^{-5}$ while the International Programme on Chemical Safety (IPCS 2002) cited $1.4 \times 10^{-3}$ as the $K_{\mathrm{H}^{\prime}}$ of NDMA. There would be significant discrepancies in the outcomes, depending on which $K_{\mathrm{H}^{\prime}}{ }^{\prime}$ is 
employed in the transport and risk assessment. At $K_{\mathrm{H}}{ }^{\prime}=$ $1.4 \times 10^{-3}$, the vapor phase diffusion of NDMA would be a dominating process in unsaturated soils and the chemical's transport through the voids would be rapid (Jury et al. I984).

The Henry's law constant is generally determined under the equilibrium conditions and there is a lack of reliable and consistent $K_{\mathrm{H}}$ measurement for potentially harmful trace chemical contaminants due to cumbersome experimental procedures. Often, it results in estimations derived from other physicochemical attributes of the compound. The equilibrium conditions are not representative of the field environment from which the volatilization takes place. Simple and straightforward methods to measure $K_{\mathrm{H}}$ of chemicals present in dilute aqueous solutions will be useful. In this study, we devised a laboratory method to determine the dimensionless Henry's law constant $\left(K_{\mathrm{H}^{\prime}}\right)$ of volatile and semi-volatile chemicals in water, based on a two boundary-layer approach, and used it to determine the $K_{\mathrm{H}}{ }^{\prime}$ of NDMA under the dynamic conditions. Factors affecting the outcomes were evaluated.

\section{MATERIALS AND METHODS}

\section{Experiment setup}

The methyl- ${ }^{14} \mathrm{C}$ labeled NDMA (specific activity $57 \mathrm{mCi}$ / mmol; radioactive purity $>99 \%$ ) was acquired from Moravek Biochemicals, USA. Stock solutions were prepared by dissolving ${ }^{14} \mathrm{C}$-NDMA in $0.01 M \mathrm{CaCl}_{2}$ solution. $200 \mathrm{ml}$ of the $70 \mu \mathrm{g} / \mathrm{L}$ NDMA aqueous solution was transferred into a $125 \mathrm{~mm}$ (diameter) by $65 \mathrm{~mm}$ (depth) glass dish and immediately placed in a fume hood operating at the room temperature $\left(20 \pm 1{ }^{\circ} \mathrm{C}\right)$. At $0,0.5,1,2,4,8,24$ and $48 \mathrm{~h}$ following the treatment, $1.0 \mathrm{~mL}$ aliquots were withdrawn using a microsyringe and immediately added into $6 \mathrm{~mL}$ of Ultima Gold scintillation cocktail. The samples were then measured for their radioactivity on a Beckman LS 1800 Liquid Scintillation Counter. The experiment was replicated three times. During the course of the experiment, the solution was continuously stirred, at $300 \mathrm{r} / \mathrm{min}$ by a magnetic stirring bar. The NDMA concentrations remaining at the preset sampling times were calculated using the measured radioactivity and the specific activity. At the same time, the weight of each glass container was determined, from which the corresponding depth of the remaining water was calculated.

\section{Mathematical modeling of $\boldsymbol{K}_{\mathrm{H}}$}

The partition of a volatile or semi-volatile compound between the atmospheric and aqueous phases may be delineated by the two boundary-layer mass transfer model (Liss \& Slater 1974). This model depicts the transfer of a compound across the atmosphere-water interface and its validity has been demonstrated by experiments in laboratory as well as observations made in natural environments including lakes, rivers and oceans (Richard I98I). In the model scheme, there is bulk water, and bulk atmosphere separated by two interfacial layers: a liquid film and a gas film.

Based on Fick's first law and assuming that transport across the gas and aqueous interfaces is a steady-state process, the flux of chemical passing through the interfacial layer $\left(F, \mathrm{~g} / \mathrm{cm}^{2} / \mathrm{h}\right)$ may described as

$F=k_{g}\left(C_{g}-C_{s g}\right)=k_{l}\left(C_{s l}-C_{l}\right)$

where $k_{g}$ and $k_{l}$ is the gas and aqueous phase exchange coefficient $(\mathrm{cm} / \mathrm{h})$, respectively, $C_{g}$ and $C_{l}$ is the concentration at the outer edge of the gas and aqueous film $\left(\mathrm{g} / \mathrm{cm}^{3}\right)$, respectively, $C_{s g}$ and $C_{s l}$ is the concentration in the gas and aqueous phase at the interface $\left(\mathrm{g} / \mathrm{cm}^{3}\right)$, respectively.

The dimensionless Henry's law constant $\left(K_{\mathrm{H}}{ }^{\prime}\right)$ is given as:

$K_{\mathrm{H}}{ }^{\prime}=C_{s g} / C_{s l}$

Therefore, $C_{s g}$ and $C_{s l}$ in Equation (1) can be obtained as:

$$
\begin{aligned}
& C_{s g}=\frac{\left[C_{g}+\left(k_{l} / k_{g}\right) C_{l}\right] * k_{g} K_{\mathrm{H}}^{\prime}}{k_{l}+k_{g} K_{\mathrm{H}^{\prime}}} \\
& C_{s l}=\left[C_{l}+\left(k_{g} / k_{l}\right) C_{g}\right] /\left(1+K_{\mathrm{H}}^{\prime}\right)
\end{aligned}
$$

Substituting Equation (3a) and (3b) into Equation (2), we can get:

$$
\begin{aligned}
F & =\left(C_{g}-K_{\mathrm{H}}{ }^{\prime} C_{l}\right) /\left(1 / k_{g}+K_{\mathrm{H}}{ }^{\prime} / k_{l}\right) \\
& =\left(C_{g} / K_{\mathrm{H}}{ }^{\prime}-C_{l}\right) /\left(1 / k_{l}+1 / K_{\mathrm{H}}{ }^{\prime} k_{g}\right)
\end{aligned}
$$

which may be written as:

$F=K_{G}\left(C_{g}-K_{\mathrm{H}}{ }^{\prime} C_{l}\right)=K_{L}\left(C_{g} / K_{\mathrm{H}}{ }^{\prime}-C_{l}\right)$ 
where $K_{G}$ and $K_{L}$ are the overall mass transfer coefficients for the gas and liquid phases $(\mathrm{cm} / \mathrm{h})$, respectively, and may be considered as the overall resistance to volatilization flux. Mathematically, $K_{G}$ and $K_{L}$ are described as:

$1 / K_{G}=1 / k_{g}+K_{\mathrm{H}}^{\prime} / k_{l}$

$1 / K_{L}=1 / k_{l}+1 / K_{\mathrm{H}}{ }^{\prime} k_{g}$

As $C_{g}=P / R T$ and $K_{\mathrm{H}}{ }^{\prime}=K_{\mathrm{H}} / R T$, Equation (5) can be rewritten as:

$F=K_{L}\left(C_{l}-P / K_{\mathrm{H}}\right)$

where $P$ is the partial pressure of the compound in the atmosphere (atm); $K_{\mathrm{H}}$ is the Henry's law constant (atm $\mathrm{m}^{3} / \mathrm{mol}$ )

Combining Equation (8) with a mass balance differential equation in an unsteady state model results in:

$\mathrm{d} C_{l} / \mathrm{d} t=-K_{L}\left(C_{l}-P / K_{\mathrm{H}}\right) / Z$

General solution of Equation (9) is:

$C_{l}=P / K_{\mathrm{H}}+\left(C_{l 0}-P / K_{\mathrm{H}}\right) \mathrm{e}^{-K_{L} t / Z}$

where $Z$ is the mean depth of the water body $(\mathrm{cm})$, and $C_{l 0}$ is the initial chemical concentration in the water body. If $P$ is negligible, Equation (10) simplifies to

$C_{l}=C_{l 0} \mathrm{e}^{-K_{L} t / z}$

Equation (11) indicates that $C_{l}$ can be described as a simple first-order exponential decay with a rate constant of $K_{L} / Z$.

\section{Calculation procedure of Henry's law constant}

Based on the experiment, the $K_{\mathrm{H}}^{\prime}$ may be calculated simply with the data on concentration changes of NDMA in the aqueous phase, $C_{l}$, and the corresponding depth of the water body, $Z$; both are function of time, $t$. First, the NDMA concentration data are fit by a least-square fitting technique to Equation (11) through which $K_{L} / Z$ may be obtained. In turn, $K_{L}$ is obtained from $K_{L} / Z$ with known $Z$. Finally, $K_{\mathrm{H}}{ }^{\prime}$ is obtained through Equation (12) that is equivalent to Equation (7).

$K_{\mathrm{H}}^{\prime}=\frac{1}{k_{g}\left(1 / K_{L}-1 / k_{l}\right)}$

where $k_{l}$ and $k_{g}$ depend on the water turbulence and wind speed, respectively.

\section{RESULTS AND DISCUSSION}

\section{Calculation of Henry's law constant of NDMA}

The changes of NDMA concentration in the water reservoir during the course of the volatilization experiment are illustrated in Figure 1(a). Measurements of replicates were highly reproducible, as evident from the very narrow data dispersions. The NDMA concentrations of the aqueous phase were fitted by the non-linear regression model according to Equation (11), which yielded a relationship of $y=$ $69.269 \mathrm{e}^{-0.0274 x}$ with $R^{2}=0.99$. Therefore, $K_{L} / Z=0.0274 \mathrm{~h}^{-1}$.

During the experiment, the water containing NDMA was continuously vaporized. Figure 1(b) shows that the water depth in the experimental containers changed linearly with time as $y(\mathrm{~cm})=-0.0113 x(\mathrm{~h})+1.6259$ with $R^{2}=0.99$. From
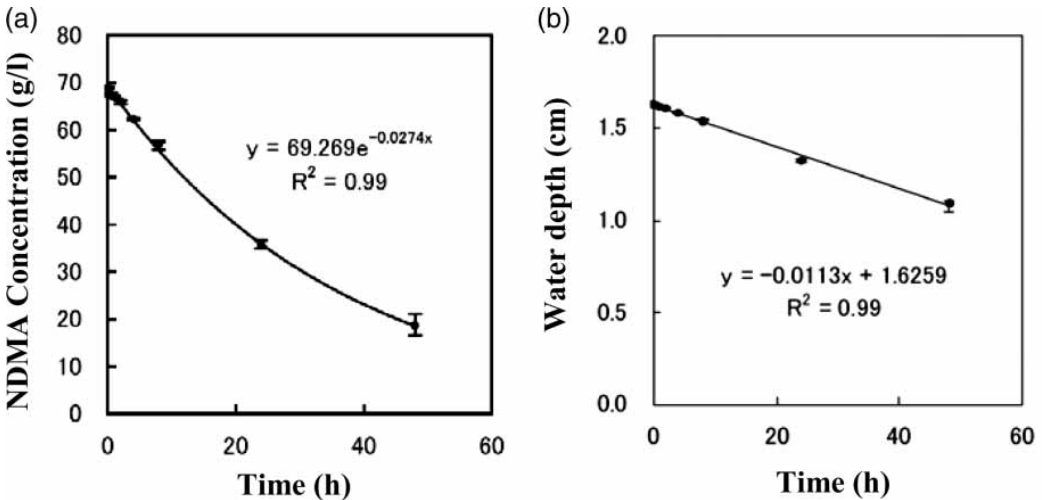

Figure 1 Change of NDMA concentrations in the liquid phase (a) and water depth (b) with respect to time under experimental conditions. 
the regression equation, the mean water depth was estimated at $1.35 \mathrm{~cm}$. As $K_{L} / Z=0.0274 \mathrm{~h}^{-1}$ and $Z=1.35 \mathrm{~cm}, K_{L}$ was calculated to be $0.0370 \mathrm{~cm} / \mathrm{h}$. The exchange coefficients $k_{g}$ and $k_{l}$ are primarily functions of wind and water turbulences, respectively (Southworth I979). Typically, $20 \mathrm{~cm} / \mathrm{h}$ for $k_{l}$ and $3,000 \mathrm{~cm} / \mathrm{h}$ for $k_{g}$ are used under the natural and experimental conditions (Liss 1973). Let $k_{l}=20 \mathrm{~cm} / \mathrm{h}$ and $k_{g}=3,000 \mathrm{~cm} / \mathrm{h}$, $K_{\mathrm{H}}{ }^{\prime}$ of NDMA is $1.24 \times 10^{-5}$, according to Equation (12).

\section{Sensitivity of $K_{\mathrm{H}^{\prime}}$ to $k_{l}$ and $k_{g}$}

The experimentally determined $K_{\mathrm{H}}{ }^{\prime}$ of NDMA may be affected by $k_{l}$ and $k_{g}$ that are not directly measured. Figure 2(a) shows the sensitivity of $K_{\mathrm{H}}$ ' to the value of $k_{l}$ whose value decreases with the increase of turbulence and it is difficult to be estimated accurately. $K_{\mathrm{H}}{ }^{\prime}$ of NDMA is not sensitive to $k_{l}$ representing the normal range of turbulence conditions in water. The resulting $K_{\mathrm{H}}{ }^{\prime}$ does not significantly change when $k_{l}$ varies from 0.6 to $100 \mathrm{~cm} / \mathrm{h}$. $k_{l}$ values are typically 1 to $3 \mathrm{~cm} / \mathrm{h}$ corresponding to a wind speed less than $3 \mathrm{~m} / \mathrm{s}$ in a natural water body (Cohen et al. 1978). Southworth (I979) obtained $0.6 \mathrm{~cm} / \mathrm{h}$ of $k_{l}$ in quiescent laboratory condition. During the experiment, the airflow velocity (i.e., wind speed) in the fume hood was approximately $0.5 \mathrm{~m} / \mathrm{s}$, which is less than $3 \mathrm{~m} / \mathrm{s}$ and the solution was continuously stirred at $300 \mathrm{r} / \mathrm{min}$. Therefore, $k_{l}=$ $2 \mathrm{~cm} / \mathrm{h}$, the average of 1 to $3 \mathrm{~cm} / \mathrm{h}$, is a realistic value for the experiment instead of the initial estimate of $20 \mathrm{~cm} / \mathrm{h}$ and is used, hereafter, in calculations of $K_{\mathrm{H}^{\prime}}$ of NDMA. When $k_{l}=2 \mathrm{~cm} / \mathrm{h}$ instead of $20 \mathrm{~cm} / \mathrm{h}, K_{\mathrm{H}^{\prime}}$ is $1.26 \times 10^{-5}$. The difference between this estimated value and initial estimate of $1.24 \times 10^{-5}$ (when $k_{l}=20 \mathrm{~cm} / \mathrm{h}$ ) is negligible.

The value of $k_{g}$ has a significant effect on the $K_{\mathrm{H}}^{\prime}$ of NDMA (Figure 2(b)). The $k_{g}$ is influenced primarily by gaseous phase and, to a lesser extent, aqueous phase mixing (Liss 1973). Its value decreases with the decrease of wind velocity (Southworth 1979). During the course of the experiment, the airflow velocity (i.e., wind speed) in the fume hood was maintained at approximately $0.5 \mathrm{~m} / \mathrm{s}$. However, the water surface was protected from the wind by $4 \mathrm{~cm}$ of freeboard above the glass dish. The actual wind velocity on the water surface would be much lower than $0.5 \mathrm{~m} / \mathrm{s}$ and might be negligible for the experiment.

Southworth (I979) obtained the $k_{g}$ of $3,000 \mathrm{~cm} / \mathrm{h}$ (the assumed value in the initial calculation) under the wind speed of $4 \mathrm{~m} / \mathrm{s}$ at a river and 3 to $4 \mathrm{~m} / \mathrm{s}$ in subsequent laboratory experiments. Southworth (I979) also showed that $k_{g}$ varied from 118 to $539 \mathrm{~cm} / \mathrm{h}$ under windless conditions when the contents were propeller mixed at speeds ranging from 0 to $200 \mathrm{r} / \mathrm{min}$ and $k_{g}$ was $964 \mathrm{~cm} / \mathrm{h}$ on the river with wind speed reached $1 \mathrm{~m} / \mathrm{s}$. These values were obtained at $25{ }^{\circ} \mathrm{C}$ for a hypothetical compound with a molecular weight of 100 . The temperature effect on $k_{g}$ may be negligible (Southworth 1979). The $k_{g}$ of two compounds is inversely proportional to the square roots of their molecular weights (Liss \& Slater 1974). Accordingly, $k_{g}$ of NDMA is expected to be approximately $14.6 \%$ higher than the hypothetical compound as the molecular weight of NDMA is 76.08 (Weast I983). Therefore, the $k_{g}$ for our experiment would be considerably smaller than the assumed value of $3,000 \mathrm{~cm} / \mathrm{h}$. Under the circumstances, it would be reasonable to assume that $k_{g}$ is one order of magnitude smaller than the initially assumed value. When $300 \mathrm{~cm} / \mathrm{h}$ was used as the $k_{g}, K_{\mathrm{H}}{ }^{\prime}$ of NDMA would be $1.26 \times 10^{-4}$ instead of $1.26 \times 10^{-5}$ for $k_{g}=3,000 \mathrm{~cm} / \mathrm{h}$. As a result, the $K_{\mathrm{H}}{ }^{\prime}$ of NDMA is most likely around $1.0 \times 10^{-4}$.

\section{Effects of water depths on Henry's law constant of NDMA}

Over the course of the experiment, the water depth of the reservoir changed from 1.65 to $1.10 \mathrm{~cm}$ as the water evaporated (Figure 1(b)). The mean water depth of $1.35 \mathrm{~cm}$ was
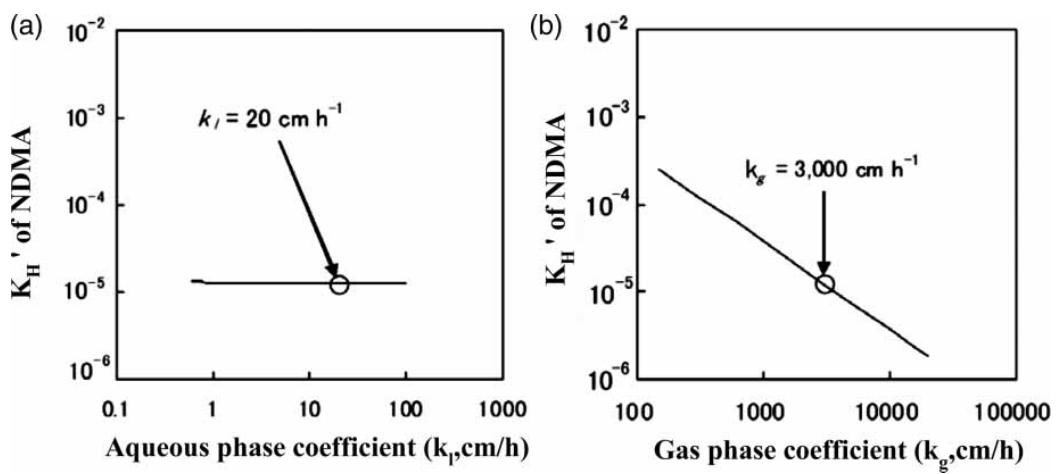

Figure 2 | Effects of aqueous phase coefficient, $k_{l}(\mathrm{a})$ and for gas phase coefficient, $k_{g}$ (b) on $K_{\mathrm{H}}{ }^{\prime}$ of NDMA. 
employed in the above $K_{\mathrm{H}}{ }^{\prime}$ calculations. The water depths may affect the NDMA concentration in the remaining water.

Figure 3 graphically illustrates the potential impacts of the unsteady water depths. In the figure, the horizontal axis represents the water depth corrected $K_{\mathrm{H}^{\prime}}$ and the vertical axis represents the $K_{\mathrm{H}}$ 'based on the average water depth of $1.35 \mathrm{~cm}$ for all of the NDMA concentrations. The corrected $K_{\mathrm{H}}^{\prime}$ corresponding to various water depths were obtained by the explicit difference method, based on

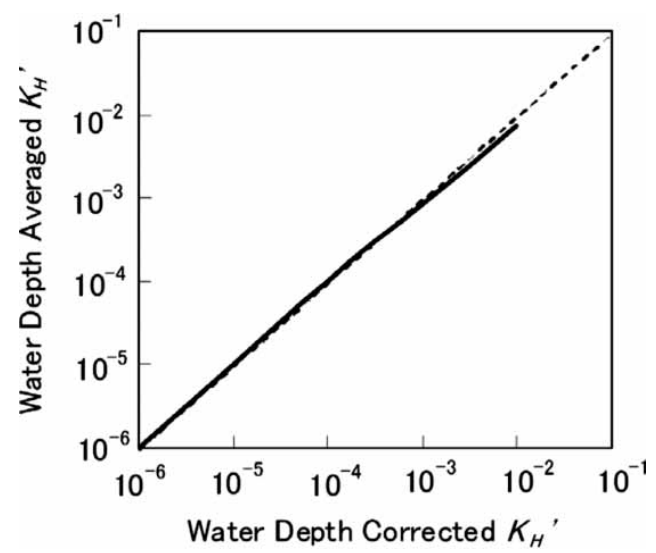

Figure 3 Experimentally determined $K_{\mathrm{H}}{ }^{\prime}$ of NDMA, water depth corrected vs. water depth averaged. The dash line in the graph represents the 1:1 line.
Equation (9). The calculated NDMA concentrations at 0.5, $1,2,4,8,24$ and $48 \mathrm{~h}$ after starting the experiments were then employed to obtain the $K_{\mathrm{H}}{ }^{\prime}$ based on the mean water depth of $1.35 \mathrm{~cm}$ by the procedure described previously with $k_{l}$ of $2 \mathrm{~cm} / \mathrm{h}$ and $k_{g}$ of $300 \mathrm{~cm} / \mathrm{h}$. The difference between the $K_{\mathrm{H}^{\prime}}$ based on the average water depth and the corrected $K_{\mathrm{H}}{ }^{\prime}$ is generally small. But the difference increase with $K_{\mathrm{H}}{ }^{\prime}$. At $K_{\mathrm{H}}{ }^{\prime}$ of $10^{-4}$ and $10^{-2}$, the underestimations are 1 and $25 \%$, respectively. As the estimated $K_{\mathrm{H}}{ }^{\prime}$ of NDMA is $1.0 \times 10^{-4}$, the expected underestimation will be approximately $1 \%$. The effects of the unsteady state water depths during the experiment on the outcomes are minor.

\section{Extension of the method}

The gas and liquid phase exchange coefficients, $k_{g}$ and $k_{l}$, and the $K_{\mathrm{H}^{\prime}}{ }^{\prime}$ characterize the volatilization process of a chemical. Through which, the overall mass transfer coefficient, $K_{L}$ corresponding to hypothetical $k_{g}, k_{l}$, and $K_{\mathrm{H}}{ }^{\prime}$ may be computed according to Equation (7). Applying the $K_{L}$ obtained and substituting $k_{g}=300 \mathrm{~cm} \mathrm{~h}^{-1}$ and $k_{l}=$ $2 \mathrm{~cm} \mathrm{~h}^{-1}$ for their respective values to Equation (11), the estimated $K_{\mathrm{H}}{ }^{\prime}$ by the method demonstrated may be obtained according to Equation (11).
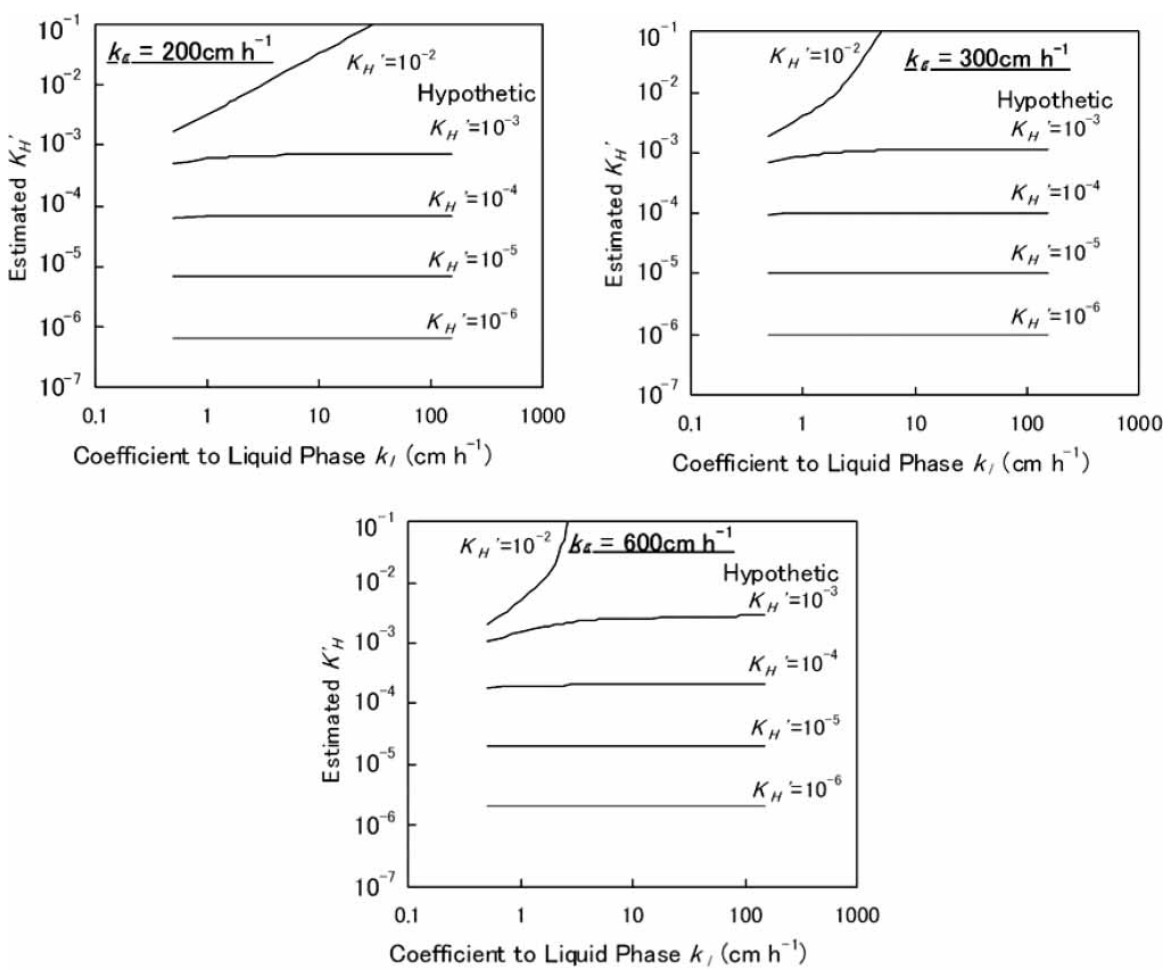

Figure 4 Hypothetical $K_{\mathrm{H}}{ }^{\prime}$ of varying $k_{\mathrm{g}}$ and $k_{l}$ vs. $K_{\mathrm{H}}{ }^{\prime}$ estimated by assuming $k_{g}=300 \mathrm{~cm} \mathrm{~h}^{-1}$ and $k_{l}=2 \mathrm{~cm} \mathrm{~h}^{-1}$. 
Figure 4 shows the comparisons of the hypothetically obtained $K_{\mathrm{H}}{ }^{\prime}$ and their respective estimates by the method we developed. For chemical compound with $K_{\mathrm{H}^{\prime}}$ equal or less than $1 \times 10^{-3}$, the estimated $K_{\mathrm{H}^{\prime}}$ are comparable to those of the hypothetical values for $k_{g}$ ranging from 200 to $600 \mathrm{~cm} / \mathrm{h}$ and $k_{l}$ ranging from less than 1 to over $100 \mathrm{~cm} / \mathrm{h}$. It is indicative that the method demonstrated is expedient to delineate the $K_{\mathrm{H}}{ }^{\prime}$ for other volatile and semi-volatile compounds.

\section{CONCLUSIONS}

We developed a simple method to estimate the dimensionless Henry's law constant, $K_{\mathrm{H}}{ }^{\prime}$, for volatile and semivolatile chemicals under non-steady conditions based on the double boundary layer mass transfer approach and tested the sensibilities of the outcomes to the mass transfer parameters. The method is applicable to compounds with $K_{\mathrm{H}}{ }^{\prime}$ less than $1.0 \times 10^{-3}$. Based on the method, the $K_{\mathrm{H}^{\prime}}$ of NDMA is around $1.0 \times 10^{-4}$. The estimated $K_{\mathrm{H}}{ }^{\prime}$ is sensitive to the gas phase coefficient, $k_{g}$. The application of the developed model can be further tested and validated for other chemicals like pyrenes which are more recognizable compounds with similar $K_{\mathrm{H}^{\prime}}$.

\section{ACKNOWLEDGEMENTS}

This work was supported by the National Natural Science Foundation of China (No. Y1B7341201) and the State Key Lab of Urban and Regional Ecology (No. SKLURE2008-1-04).

\section{REFERENCES}

Arienzo, M., Gan, J., Ernst, F., Yang, W. C. \& Sedlak, D. L. 2006 Loss pathways of $N$-Nitrosodimethylamine (NDMA) in turfgrass soils. J. Environ. Qual. 35, 285-292.

CDHS (California Department of Health Services) 2006 DHS Drinking Water Notification Levels. Available from: http:// www.cdph.ca.gov/certlic/drinkingwater/Pages/ NotificationLevels.aspx (verified 2011.06.30).

Cohen, Y., Cocchino, W. \& Mackay, D. 1978 Laboratory study of liquid-phase controlled volatilization rates in presence of wind waves. Environ. Sci. Technol. 12, 553-558.
Gan, J., Bondarenko, S., Ernst, F., Yang, W., Bries, S. \& Sedlak, D. L. 2006 Leaching of $N$-Nitrosodimethylamine (NDMA) in turfgrass soils during wastewater irrigation. J. Environ. Qual. 35, 277-284

Gunnison, D., Zappi, M. E., Teeter, C., Pennington, J. C. \& Bajpai, R. 2000 Attenuation mechanisms of $\mathrm{N}$-Nitrosodimethylamine at an operating intercept and treat groundwater remediation system. J. Hazard. Mater. 73, 179-197.

Haruta, S., Chen, W. P., Gan, J., Šimůnek, J., Chang, A. C. \& Wu, L. S. 2008 Leaching risk of $N$-Nitrosodimethylamine (NDMA) in soil receiving reclaimed wastewater. Ecotox. Environ Safe 69, 374-380.

IPCS (International Programme on Chemical Safety) 2002 $\mathrm{N}$-Nitrosodimethylamine (NDMA). Concise International Chemical Assessment Document 38.

Jury, W. A., Farmer, W. J. \& Spencer, W. F. 1984 Behavior assessment model for trace organics in soil: II. Chemical classification and parameter sensitivity. J. Environ. Qual. 13, 567-572.

Liss, P. S. 1973 Processes of gas exchange across an air-water interface. Deep Sea Res. 20, 231-238.

Liss, P. S. \& Slater, P. G. I974 Flux of gases across the air sea interface. Nature 247, 181-184.

Mirvish, S. S., Issenberg, P. \& Sornson, H. C. 1976 Air-water and ether-water distribution of N-Nitroso compounds: implications for laboratory safety, analytical methodology, and carcinogenicity for the rat esophagus, nose, and liver. J. Natl Cancer I. 56, 1125-1129.

Mitch, W. A. \& Sedlak, D. L. 2002a Factors controlling nitrosamine formation during wastewater chlorination. Water Sci. Tech. Water Supply 2, 191-198.

Mitch, W. A. \& Sedlak, D. L. 2002b Formation of $\mathrm{N}$-Nitrosodimethylamine (NDMA) from dimethylamine during chlorination. Environ. Sci. Technol. 36, 588-595.

Oliver, J. E. 1979 Volatilization of some herbicide-related nitrosamines from soils. J. Environ. Qual. 8, 596-601.

Pehlivanoglu, E. \& Sedlak, D. L. 2004 Bioavailability of wastewater-derived organic nitrogen to the alga Selenastrum Capricornutum. Water Res. 38, 3189-3196.

Richard, G. T. I98I Volatilization from water. In: Handbook of Chemical Property Estimation Method - Environmental Behavior of Organic Compounds (W. J. Lyman, W. F. Reehl \& D. H. Rosenblatt, eds.). McGraw-Hill, New York.

Southworth, G. R. I979 The role of volatilization in removing polycyclic aromatic hydrocarbons from aquatic environments. B. Environ. Contam. Tox. 21, 507-514.

Weast, R. C. 1983 Handbook of Chemistry and Physics. 64th edition, CRC Press, Boca Raton, FL.

Yang, W. C., Gan, J., Liu, W. P. \& Green, R. 2005 Degradation of $N$-Nitrosodimethylamine (NDMA) in landscape soils. J. Environ. Qual. 34, 336-341. 